\title{
Differentiating Vaccine-Related Fowl Cholera from Naturally Occurring Disease
}

\author{
Anna R. Hutcheson, ${ }^{\text {A }}$ Kasey Thompson, ${ }^{\mathrm{B}}$ John J. Maurer, ${ }^{\mathrm{C}}$ Naola Ferguson, Karen Grogan, Stephen Roney, ${ }^{\mathrm{D}}$ \\ Harmony Seahorn, Chris Lobsinger, and Margie D. Lee ${ }^{\mathrm{E}}$ \\ Poultry Diagnostic and Research Center, The University of Georgia, Athens, GA 30601
}

Received 25 February 2020; Accepted 18 May 2020; Published ahead of print 18 May 2020

\begin{abstract}
SUMMARY. Vaccine-related fowl cholera must be considered when flock mortality increases after use of a live Pasteurella multocida vaccine product. All registered live vaccines serotype as Heddleston 3,4; however, in some regions this is also the most common serotype of outbreak isolates in broiler breeders and turkeys. Therefore, serotyping may not be useful for diagnosing vaccine-related fowl cholera. This project sought to apply a vaccine-specific test to differentiate vaccine-related disease from naturally occurring outbreaks. Results indicate that vaccine strains were commonly isolated from broiler breeders exhibiting signs of fowl cholera postvaccination, but some of these isolates exhibited only serotype 4 antigenicity. The isolates' lipopolysaccharides, the target antigen for serotyping, contained compositional changes that may explain the varying serotype results and virulence of the commercial preparations. These results suggest that vaccine-related disease may be common in broiler breeders, and live commercial vaccine preparations need to be assessed for serotype and titer prior to use in order to reduce vaccine-related fowl cholera.
\end{abstract}

RESUMEN. Diferenciación de cólera aviar relacionado con vacunación de la presentación natural de la enfermedad.

La presentación de cólera aviar relacionada con vacunación debe considerarse cuando la mortalidad de la parvada aumenta después del uso de un producto vivo de la vacuna de Pasteurella multocida. Todas las vacunas vivas registradas son serotipo Heddleston 3,4; sin embargo, en algunas regiones este es también el serotipo más comúnmente aislado de brotes en reproductores de pollos de engorde y pavos. Por lo tanto, la serotipificación puede no ser útil para diagnosticar las presentaciones de cólera aviar relacionadas con la vacuna. Este proyecto buscó aplicar una prueba específica para la vacuna para diferenciar la enfermedad relacionada con la vacunación de los brotes naturales. Los resultados indican que las cepas de vacuna se aislaron comúnmente de los reproductores de pollos de engorde que exhibían signos de cólera aviar después de la vacunación, pero algunos de estos aislamientos exhibían solo antigenicidad del serotipo 4. Los lipopolisacáridos de los aislamientos, el antígeno objetivo para la serotipificación, contenían cambios en la composición que pueden explicar los diferentes resultados del serotipo y virulencia de las preparaciones comerciales. Estos resultados sugieren que la enfermedad relacionada con la vacuna puede ser común en los reproductores pesados y las preparaciones de vacunas comerciales vivas deben evaluarse para el serotipo y el título antes de su uso con el fin de reducir la presentación de cólera aviar relacionada con la vacuna.

Key words: Pasteurella multocida, fowl cholera, serotype, vaccine, lipopolysaccharides, PCR, lectin

Abbreviations: $\mathrm{BHI}=$ brain heart infusion; BLAST = Basic Local Alignment Search Tool; CRISPR $=$ clustered regularly interspaced short palindromic repeats; CU = Clemson University; GC-MS = gas chromatography-mass spectrometry; LPS = lipopolysaccharide; PFGE = pulsed-field gel electrophoresis; RAST = Rapid Annotation using Subsystem Technology; SBA = soybean agglutinin; SDS-PAGE = sodium dodecyl sulfate polyacrylamide gel electrophoresis; TMS = trimethylsilyl; TTBS = Triton Tris buffered saline; w/v = weight/volume

Pasteurella multocida causes a wide range of disease in mammals and birds (1) including the septicemic disease known as fowl cholera (2). Clinical findings vary depending on the course of disease and species affected but can be classified as acute or chronic (3). A first indication of acute fowl cholera is high mortality, while chronic symptoms include depression, anorexia, and swollen wattles and joints. Turkeys are more susceptible than chickens, and mature birds

\footnotetext{
${ }^{A}$ Present address: Research Service, Atlanta Veterans Affairs Medical Center, Decatur, GA, 30033

${ }^{B}$ Present address: USDA Food Safety Inspection Service, Athens, GA, 30605

C Present address: Virginia Tech, Animal and poultry Science, Blacksburg, VA 24061

D Present address: CSR Poultry Health Consulting, Midland City, AL 36350

${ }^{\mathrm{E}}$ Corresponding author. Present address: Virginia Tech, Biomedical Sciences and Pathobiology, 205 Duckpond Drive, Blacksburg VA, 24060. E-mail: Mlee2@vt.edu
}

are more susceptible than adolescent birds. Fowl cholera can cause great economic impact in the poultry industry, and $P$. multocida cannot be eradicated from flocks with antibiotics. Fowl cholera usually recurs after treatment $(4,5)$.

A diagnosis of fowl cholera is generally done by culture, but serotyping is needed in identifying the source of the organism in outbreaks and selecting isolates for killed vaccine. Pasteurella multocida is classified into 16 somatic lipopolysaccharide (LPS) serotypes by Heddleston gel diffusion precipitin test, the gold standard for serotyping P. multocida (6,7). Pasteurella multocida can also be classified by capsular composition (A, B, D, E, F), but since most poultry strains are capsule $A$ or $D$, it is not useful in differentiating outbreak strains $(8,9)$. Serotypes commonly isolated from fowl cholera outbreaks are 1,3, and 4, although cross reactivity in P. multocida isolates (for example: 3,4 or $1,3,4$ ) is frequently seen (10).

Birds can be vaccinated with killed or live vaccine products. Live vaccines protect against heterologous serotypes, while killed vaccines do not. There are three $P$. multocida live vaccines available on the 
Table 1. Pasteurella multocida strains and isolates.

\begin{tabular}{|c|c|c|c|c|}
\hline Strains & Background & Serotype & PCR results & Reference \\
\hline Clemson & live vaccine, originally turkey avirulent field isolate & 3,4 & positive & $(13,17)$ \\
\hline PM-1 & live vaccine, chemically induced mutant of CU & 3,4 & positive & $(11)$ \\
\hline M-9 & live vaccine, chemically induced mutant of $\mathrm{CU}$ & 3,4 & positive & $(12)$ \\
\hline $92-67-2$ & 31-wk-old broiler breeder chickens; associated with septic arthritis, peritonitis, and perihepatitis & 3,4 & negative & (15) \\
\hline $92-2667$ & 29-wk-old broiler breeder chickens; associated with peritonitis and enteritis & 3,4 & negative & $(15)$ \\
\hline $86-1913$ & peracute turkey fowl cholera & 3,4 & negative & $(15)$ \\
\hline P-1059 & Heddleston type strain & 3 & negative & $(6)$ \\
\hline P-1662 & Heddleston type strain & 4 & negative & $(6)$ \\
\hline P-1702 & Heddleston type strain & 5 & negative & (6) \\
\hline P-2192 & Heddleston type strain & 6 & negative & (6) \\
\hline P-1997 & Heddleston type strain & 7 & negative & (6) \\
\hline P-1581 & Heddleston type strain & 8 & negative & (6) \\
\hline P-1591 & Heddleston type strain & 13 & negative & (6) \\
\hline P-2225 & Heddleston type strain & 14 & negative & (6) \\
\hline P-2237 & Heddleston type strain & 15 & negative & (6) \\
\hline P-2723 & Heddleston type strain & 16 & negative & (6) \\
\hline
\end{tabular}

market, the Clemson University (CU) vaccine strain, PM-1, and M9, which are slow-growing, heat sensitive attenuated derivatives of CU $(11,12,13)$. All three of these live vaccines serotype as a 3,4, and they therefore cannot be differentiated from 3,4 environmental outbreak strains. In addition, Heddleston gel diffusion precipitin test can exhibit issues with reproducibility and reliability. A multiplex PCR that can detect LPS by genotype (L1-L8) has been described; however, it cannot differentiate vaccine-related fowl cholera from natural disease, nor can it distinguish between serotype 3 and 4 isolates (14).

Previous studies have shown genetic differences between vaccine strains and outbreak 3,4 strains in turkeys $(15,16)$. And because live vaccines can cause fowl cholera if used incorrectly, the objective of this study was to develop a vaccine-specific test to detect vaccinerelated fowl cholera from naturally occurring outbreaks. Comparative genomics were used to develop a vaccine-specific PCR, which was used to investigate the prevalence of clinical disease caused by commercial vaccine preparations. The vaccine-specific PCR not only detected vaccine-related fowl cholera in 3,4 outbreaks but determined that some vaccine outbreaks occurred from serotype 4 isolates. These isolates expressed a modified LPS, which affected serotyping and increased their virulence in broiler breeder chickens.

\section{MATERIALS AND METHODS}

Isolates and strains. Pasteurella multocida vaccine strains (CU, PM1 , and M-9), five previously studied 3,4 isolates that are genetically different from the CU vaccine strain (93-182, 92-67-2, 92-2667, 861913, and 91-1792) (15), and Heddleston serotypes 1-16 (excluding serotype 2) type strains were used to develop vaccine-specific PCR primers (Table 1). Forty-seven outbreak isolates from the University of Georgia's Poultry Diagnostic and Research Center were used to investigate vaccine-related fowl cholera using the vaccine-specific PCR. Bacteria were cultured on $5 \%$ sheep blood agar or in brain heart infusion (BHI) broth and incubated at $37 \mathrm{C}$ overnight. Two commercial vaccine lots (serial numbers: 00651363B [M-9-63B] and 00651360A
[M-9-60A]) were acquired from poultry companies that were experiencing suspect fowl cholera vaccine outbreaks. Vaccines were stored at $4 \mathrm{C}$ per manufacturer's recommendation, but in addition, an aliquot was removed and stored, similarly to the bacterial isolates, as glycerol stocks at $-80 \mathrm{C}$.

Vaccine-specific PCR. Ten units of hyaluronidase per $1 \mathrm{ml}$ were added to standing overnight cultures in BHI broth once an optical density $600=10^{8}$ was reached (18). They were then incubated for $1-2$ $\mathrm{hr}$ at $37 \mathrm{C}$ for capsule removal. DNA extraction was done using Wizard ${ }^{\circledR}$ Genomic DNA purification kit (Promega, Madison, WI), then purified DNA was submitted to the Molecular Genetics Instrumentation Facility at the University of Georgia for whole genome sequencing. Illumina genome libraries were produced for Clemson and the five previously characterized 3,4 outbreak isolates (Table 1). Raw data sequences were cleaned for adapter contamination and quality using FastQC (19), and sequence libraries were trimmed to remove low quality reads using FastaQ/A Trimmer in FASTX Toolkit (20). Assembly of paired-end Illumina reads was done using Spades sequence assembly tool (21).

Genome sequences were uploaded and annotated in Rapid Annotation using Subsystem Technology (RAST) (22). The annotated genomes were searched for DNA sequences unique to the vaccine strain using the RAST genome comparison tool. The clustered regularly interspaced short palindromic repeats (CRISPR) cas2 locus intergenic region between cas 2 and a gene that was annotated as a phage tail was selected for comparison. A DNA sequence alignment was done using Clustal Omega (23) and MEGA (24) to identify CU specific sequences, and Basic Local Alignment Search Tool (BLAST) (25) was used as initial confirmation that it was unique to vaccine strains. PCR primers were designed targeting the $\mathrm{CU}$ vaccine strain specific CRISPR sequence using Primer 3 Plus (26) resulting in the primer sequences (Primer 1 AGAAACGCAATGGAATACCG; Primer 2 TGCCGCAGTTGTTGTAGTTC). The amplicon sequence was deposited in GenBank as Accession MT347697.

Boiled templates $(1 \mu \mathrm{l})$ of isolates were used in a $9 \mu \mathrm{l}$ PCR reaction mixture that consisted of $0.2 \mathrm{mM}$ deoxynucleotides, $3.0 \mathrm{mM} \mathrm{MgCl}_{2}$, $12.5 \mathrm{mM}$ for each primer, and 0.5 units of Taq DNA polymerase (Denville Scientific, Holliston, MA). The samples were placed in an 
Idaho Rapidcycler with the following parameters: $94 \mathrm{C}$ for $1 \mathrm{~min}, 94 \mathrm{C}$ for $0 \mathrm{sec}, 55 \mathrm{C}$ for $0 \mathrm{sec}$, and $72 \mathrm{C}$ for $15 \mathrm{sec}$ for 30 cycles at a slope of 2 . Amplicons were analyzed by gel electrophoresis on a $1.5 \%$ agarose and Tris acetate EDTA buffer ( $40 \mathrm{mM}$ Tris, $20 \mathrm{mM}$ acetate, $1 \mathrm{mM}$ EDTA) gel with ethidium bromide $(0.2 \mathrm{mg} / \mathrm{ml})$ at 100 volts for $45 \mathrm{~min}$. A 100 base pair ladder (Promega, Madison, WI) served as a molecular size standard for determining molecular weights of PCR products.

Strain typing by pulsed-field gel electrophoresis. Pulsed-field gel electrophoresis (PFGE) was used to determine strain distribution among the outbreak isolates. Isolates were cultivated on BHI plates overnight, resuspended in BHI broth, and capsule removed with hyaluronidase treatment as described above. Cells were embedded in agarose, genomic DNA isolated, and digested overnight with 10 units of restriction enzyme Apa 37 C (27). DNA fragments were separated in a $1 \%$ gel with a voltage of 6 volts $/ \mathrm{cm}$ and a linearly ramped pulse time of 2.2 to $63.8 \mathrm{sec}$ for $15.5 \mathrm{hr}$ in Tris borate EDTA buffer containing thiourea (1.0 mM) (28). A database of P. multocida PFGE patterns was generated using BioNumerics (Applied Maths; Austin, TX), and comparisons were made using the Dice coefficient.

Lipopolysaccharide analysis. Isolates for study were cultivated on $5 \%$ blood agar plates at $37 \mathrm{C}$ overnight. Three to five colonies were tapped with sterile inoculation loops, transferred to BHI broth, and grown overnight at $37 \mathrm{C}$ to a concentration of $10^{8}$ per milliliter. Capsule was removed by hyaluronidase treatment, and cells were washed with phosphate buffered saline (137 $\mathrm{mM} \mathrm{NaCl}, 10 \mathrm{mM}$ phosphate, 2.7 $\mathrm{mM} \mathrm{KCl}, \mathrm{pH} 7.5$ ) and pelleted by centrifugation for $3 \mathrm{~min}$ at $10,000 \times$ g. Samples were then suspended into $50 \mu \mathrm{l}$ of sodium dodecyl sulfate polyacrylamide gel electrophoresis (SDS-PAGE) lysis buffer as described by Hitchcock and Brown (29), boiled for $10 \mathrm{~min}$, cooled to room temperature, then treated with $25 \mu \mathrm{g}$ of Proteinase $\mathrm{K}$ at $60 \mathrm{C}$ for $1 \mathrm{hr}$.

LPS sample preparations were subjected to SDS-PAGE in $15 \%$ acrylamide (weight/volume $[\mathrm{w} / \mathrm{v}]$ ) separating gel containing $2.6 \%$ Bis $(\mathrm{w} / \mathrm{v}), 2 \mathrm{M}$ of urea, and $0.4 \%$ of $\mathrm{NaCl}$ on a Bio-Rad Mini-PROTEAN system at $24 \mathrm{~mA}$, constant current. Gels were incubated overnight in $40 \%$ ethanol and $5 \%$ acetic acid solution, then treated with $7 \%$ sodium metaperiodate, $40 \%$ ethanol, and $5 \%$ acidic acid for $5 \mathrm{~min}$. Afterward, gels were washed three times for $15 \mathrm{~min}$ with deionized water before staining gels using Silver Stain Plus kit (Bio-Rad, Hercules, CA) to visualize LPS bands. Molecular weight marker of $27-1.4 \mathrm{kDa}$ polypeptide SDS-PAGE standard (Bio-Rad, Hercules, CA) was used to determine relative migration and calculate size of the LPS bands.

Unstained gels were transferred to polyvinylidene fluoride membranes (Bio-Rad, Hercules, CA) using the methods of Towbin et al. (30) then probed with serotype 3 or 4 antiserum acquired from the National Veterinary Services Laboratory (Ames, IA) as described by Coy et al. (31). Soybean agglutinin (SBA) from Glycine max (Vector Labs, Burlingame, CA) lectin blots were performed as described by Coy et al. with the following modifications. Membranes were probed with biotinylated lectin $5-10 \mu \mathrm{g} / \mathrm{ml}$, diluted in Triton Tris buffered saline (TTBS; $0.9 \% \mathrm{NaCl}, 100 \mathrm{mM}$ Tris, $0.1 \%$ Tween-20). Membranes were blocked with $2 \%$ gelatin in TTBS for $1 \mathrm{hr}$ in $25 \mathrm{C}$. Membranes were placed in lectin solution for $1 \mathrm{hr}$ and then washed three times with TTBS for $10 \mathrm{~min}$. Membranes were placed in a solution of 1:30,000 dilution of goat anti-biotin antibody conjugated with alkalinephosphatase (Sigma-Aldrich, St. Louis, MO) for $1 \mathrm{hr}$ in TTBS then washed three times for $10 \mathrm{~min}$ and developed in fast-red substrate solution (Sigma-Aldrich, St. Louis, MO). The development was stopped with sterile water once the positive controls were detected. After transfer, the lane containing the polypeptide size markers was cut from the membrane and stained with Ponceau $S$ to visualize bands and verify transfer of molecules. SBA binding preference and specificity is terminal $\alpha$ - and $\beta$ - $N$-acetyl-D-galactosamine (32).

Colony blots of $10^{1}-10^{5}$ colony forming units per plate were performed on bacteria grown overnight on BHI agar to determine whether the distribution of serotype 3 and 4 antigens within commercial vaccine preps was uniform. Colonies were adsorbed onto nitrocellulose squares that were placed onto plates; in some experiments, colonies were grown on top of $82 \mathrm{~mm}$ circular nitrocellulose membranes for $48 \mathrm{hr}$. Membranes were exposed to chloroform vapors for $20 \mathrm{~min}$ overnight. The membranes were then probed using the methods described above. Strain X-73 (serotype 1) used a negative control to detect nonspecific binding of serotype 3 and 4 antibody or SBA lectin.

Glycosyl composition analysis was performed by combined gas chromatography-mass spectrometry (GC-MS) of the per-O-trimethylsilyl (TMS) derivatives of the monosaccharide methyl glycosides produced from the acid-hydrolyzed samples by acidic methanolysis as described previously by Santander et al. (33). The samples ( 200-400 $\mu \mathrm{g}$ each) were spiked with $20 \mu \mathrm{g}$ of inositol (internal standard) and heated with $1 \mathrm{M}$ methanolic $\mathrm{HCl}$ in a sealed screw-top glass test tube for $18 \mathrm{hr}$ at $80 \mathrm{C}$. After cooling and removal of the solvent under a stream of nitrogen, the samples were treated with a mixture of methanol, pyridine, and acetic anhydride for $30 \mathrm{~min}$. The solvents were evaporated, and the samples derivatized with Tri-Sil HTP (Pierce, Dallas, TX) at $80 \mathrm{C}$ for $30 \mathrm{~min}$. GC-MS analysis of the resulting TMS methyl glycosides was performed on an Agilent 7890A GC interfaced to a 5975C MSD, using an Supelco Equity-1 fused silica capillary column (30 $\mathrm{m} \times 0.25 \mathrm{~mm}$ internal diameter). Glycosyl composition analysis was performed at the analytical services lab of the University of Georgia Complex Carbohydrate Research Center.

DNA sequences and accession numbers. Whole genome sequences were deposited in the National Center for Biotechnology Information (NCBI), including genomes for $P$. multocida isolates Clemson (JABBJK00000000), 86-1913 (JABCJN00000000), 92-672 (JABCJO00000000), 92-2667 (JABCJP00000000), and 93-182 (JABCJQ000000000). The Clemson strain CRISPR PCR amplicon was deposited as GenBank Accession MT347697.

\section{RESULTS}

A comparison of genome sequences among $P$. multocida vaccine strain CU and five 3,4 field isolates identified several sequences unique to the $\mathrm{CU}$ vaccine. The 3,4 field isolates were chosen because a previous epidemiologic study using restriction fragment length polymorphism had shown that they were genetically distinct from the CU vaccine strain but likely related enough to provide useful genomic comparisons (15). The CRISPR genes were particularly promising because these loci often contain significant sequence variability useful for molecular typing (34). Sequence alignment of one of the unique regions containing a CRISPR, the intergenic region between cas2, and the annotated phage tail gene revealed likely unique vaccine strain sequences. This CRISPR sequence was then compared to all P. multocida genomes deposited at NCBI using BLAST resulting in only one hit to a deposited vaccine strain genome. A PCR was developed and optimized to confirm its presence in CU, M-9, and PM-1. The vaccine strains were positive in the vaccine-specific PCR, and all of the Heddleston type strains were negative (Table 1 ).

The vaccine-specific PCR was then used to evaluate 47 field isolates archived at the University of Georgia Poultry Diagnostic Lab. These included $P$. multocida isolates from 34 broiler breeder flock outbreaks, 5 turkey, 1 duck, 2 pheasant, 1 layer breeder, 1 layer, 1 quail, 1 turkey breeder, and 1 backyard chicken case. Twenty-three isolates serotyped as 3,4, five serotyped as 3, and eighteen serotyped as 4 (Table 2).

Thirty-six percent of the field isolates (17/47) were positive in the vaccine-specific PCR, which included 43\% serotyped 3,4 (10/23) and $37 \%$ serotyped 4 (7/19). No PCR positives were detected 
Table 2. Pasteurella multocida outbreak isolates characterized with vaccine-specific PCR.

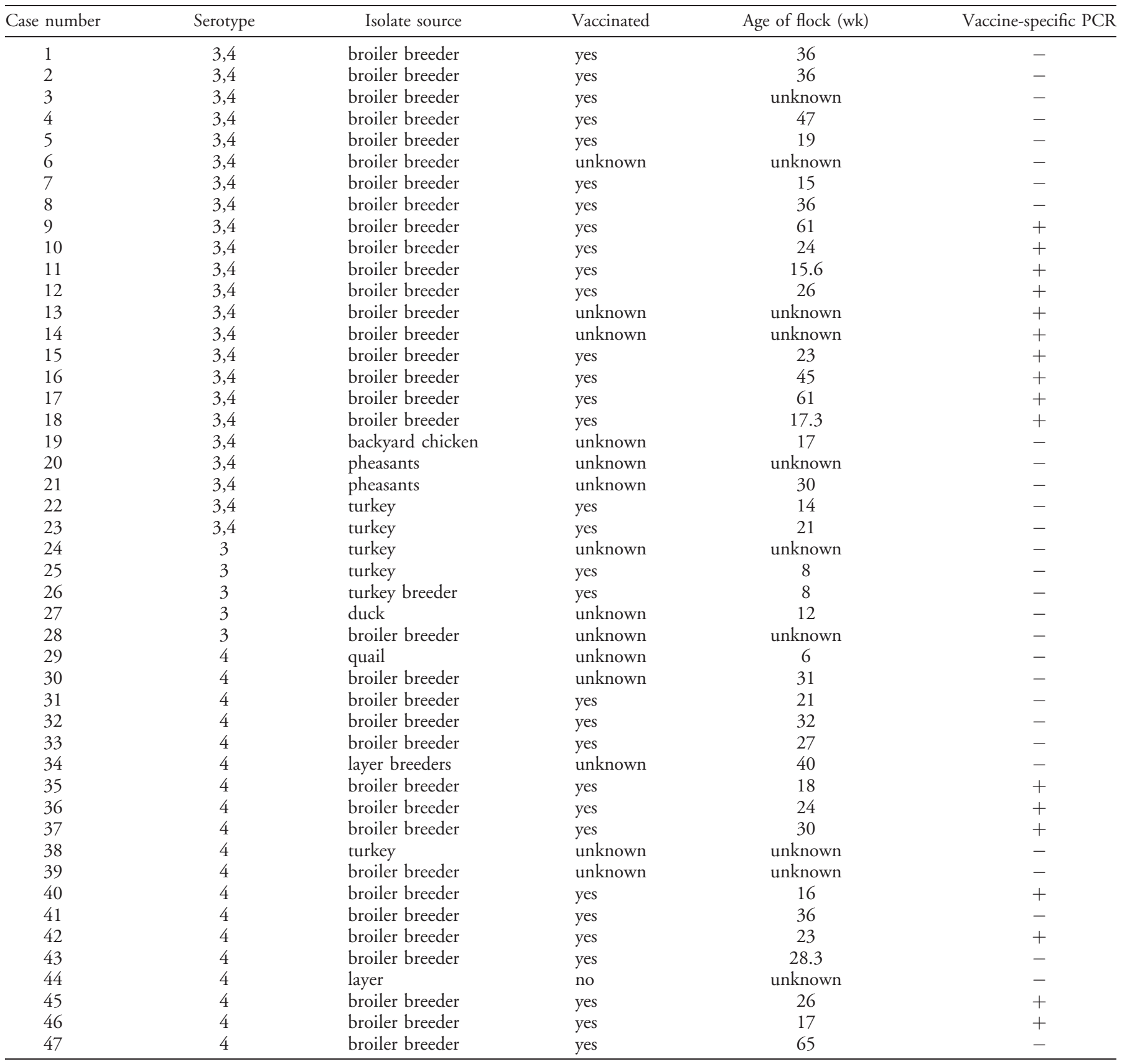

among serotype 3 field isolates. Seventy-eight percent of the serotype 3,4 isolates $(18 / 23)$ and $79 \%$ of serotype 4 isolates (15/19) were cultured from broiler breeders. In fact, all of the PCR-positive isolates were cultured from broiler breeders, and these results suggest that approximately half of serotype 3,4 (10/15) and serotype 4 isolates (7/13) cultured from vaccinated broiler breeders were involved in vaccine-related outbreaks. All broiler breeder flocks from which PCR-positive isolates were cultured and in which age was recorded were older than $16 \mathrm{wk}$. All isolates from other species of birds were negative in vaccine-specific PCR.

PFGE was used to confirm the vaccine strain type among PCRpositive isolates (Fig. 1). All PCR-positive isolates exhibited 100\% relatedness with CU, M-9, and PM-1, while negative PCR isolates exhibited less than $82 \%$ relatedness. The vaccine-specific PCR's sensitivity was $80.49 \%$ to $100.00 \%$ and specificity was $88.43 \%$ to $100.00 \%$, with a confidence interval of $95 \%$.

Because some of the PCR-positive isolates were cultured from recent cases of fowl cholera, the referring veterinarian submitted two vaccine lots for analysis. Heddleston serotyping of cells acquired from the commercial vaccine revealed that both lots primarily contained serotype 4 cells instead of 3,4, as would be expected from an M-9 live vaccine. Aliquots of each lot were plated in order to acquire isolated colonies that were screened by immunoblotting to determine the distribution of 3 or 4 or 3,4 colony types. Colony blots revealed that the commercial vaccine preps contained cells reactive with both antisera and were not a mix of serotype 3 and 4 cells (data not shown). Vaccine lot M-9-63B colonies exhibited a weak reaction to serotype 3 antisera but were positive when 

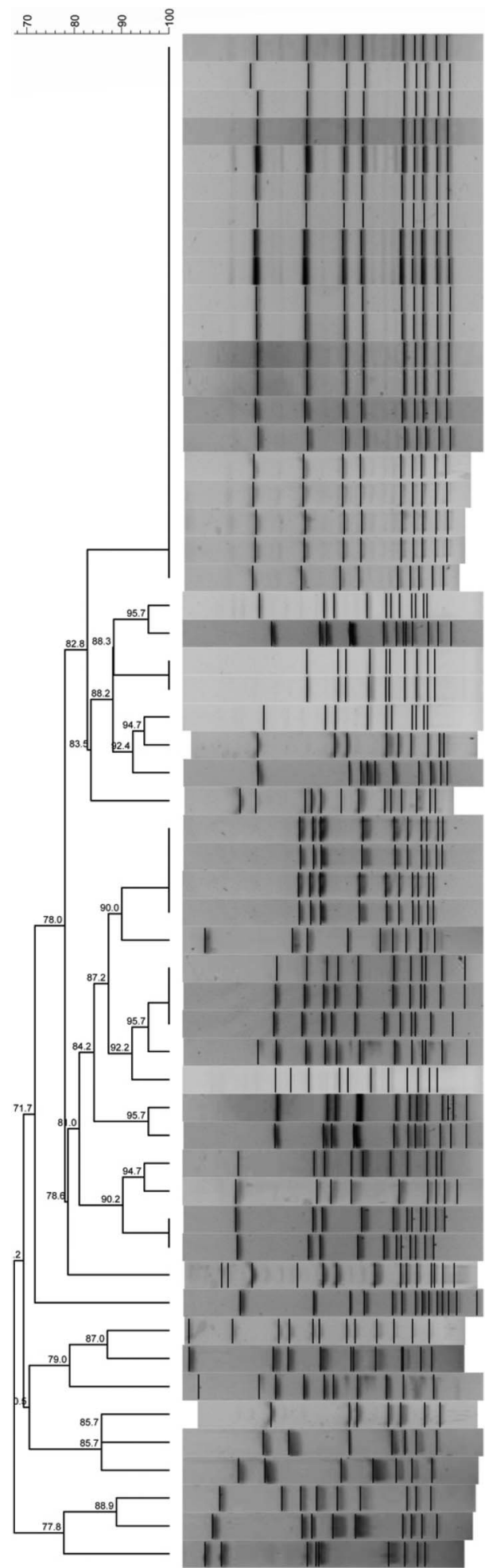

PM-1 Vaccine Strain Clemson University M-9 Vaccine Strain PCR Positive 11 PCR Positive 42 PCR Positive 35 PCR Postive 36 PCR Positive 37 PCR Positive 45 PCR Positive 46 PCR Positive 40 PCR Positive 12 PCR Positive 10 PCR Positive 13 PCR Positive 9 PCR Positive 14 PCR Positive 15 PCR Positive 16 PCR Positive 17 PCR Positive 18 93-182

PCR Negative 43 91-1792 92-67-2

86-1913

PCR Negative 22

PCR Negative 7

PCR Negative 19

PCR Negative 1

PCR Negative 2

PCR Negative 38

PCR Negative 39

PCR Negative 25

PCR Negative 5

PCR Negative 4

PCR Negative 28

PCR Negative 3

92-2667

PCR Negative 6

PCR Negative 44

PCR Negative 23

PCR Negative 24

PCR Negative 47

PCR Negative 41

PCR Negative 21

PCR Negative 8

PCR Negative 20

PCR Negative 27

PCR Negative 34

PCR Negative 30

PCR Negative 33

PCR Negative 32

PCR Negative 26

PCR Negative 31

PCR Negative 29

Fig. 1. PFGE strain-typing of Pasteurella multocida outbreak isolates and vaccine strains. Serotype is shown to the right of the isolate numbers.

compared with the negative control X-73 (serotype 1). When colonies were probed with SBA lectin, specific for terminal $N$-acetylgalactosamine residues associated with the serotype 3 LPS (35), colonies from the commercial vaccine lots were positive; however, CU's colonies were not.

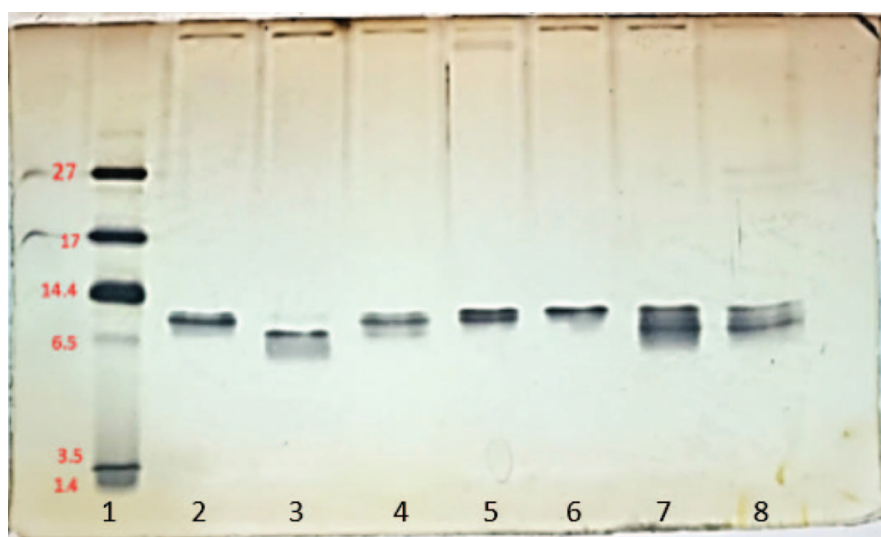

Fig. 2. Molecular weight of LPS isolated from vaccine strains and vaccine preparations. Lane 1: molecular weight standard. Lane 2: P1059 (serotype 3). Lane 3: P1662 (serotype 4). Lane 4: CU vaccine strain. Lane 5: PM-1 vaccine strain. Lane 6: M-9 vaccine strain. Lane 7: commercial vaccine lot M-9-63B. Lane 8: commercial vaccine lot M-9$60 \mathrm{~A}$.

Because the nature of serotype specificity is believed to be LPS composition, gel electrophoresis was used to estimate size differences among the isolates' LPS and predict distribution of serotype 3 and 4 LPS. Harper et al. (2017) reported the carbohydrate structure of all of the $P$. multocida serotype type strains' LPS, enabling estimation of molecular weights (36). Approximate molecular weight for each LPS band was determined by relative migration compared with the molecular weight standards (Fig. 2). Pasteurella multocida P1059 (serotype 3) had two bands of approximately 7.8 and $7.5 \mathrm{kDa}$. The molecular weight suggests that the $7.5 \mathrm{kDa}$ band represents serotype 3 outer core LPS containing one terminal $N$-acetyl-galactosamine, while the $7.8 \mathrm{kDa}$ band contains a second $N$-acetyl-galactosamine molecule. P1662 (serotype 4) exhibited a band of $6.3 \mathrm{kDa}$ and one faint band of $7.5 \mathrm{kDa}$. CU exhibited 3 bands of 7.8, 7.5 (major band), and $6.3 \mathrm{kDa}$ as expected for a 3,4 serotype; however, M-9 had only one band of $7.8 \mathrm{kDa}$ (serotype 3 LPS) and PM-1 had two similar molecular weight bands at 7.8 and $7.5 \mathrm{kDa}$, representing serotype 3 LPS. The commercial vaccine preps exhibited the same three bands as $\mathrm{CU}$, suggesting the presence of both 3 and 4 serotype LPS.

Serotype 3 and 4 antisera were used to probe LPS bands to confirm their predicted identity (Table 3). CU, PM-1, and M-9 bands of sizes 7.8 and $7.5 \mathrm{kDa}$ LPS reacted with serotype 3 antiserum as predicted (Fig. 3, Panel A). None of the LPS bands from commercial vaccine preparations reacted with serotype 3 antiserum; however, the $6.3 \mathrm{kDa}$ bands did react with serotype 4 antiserum (Fig. 3, Panel B). CU, PM-1, and M-9 reacted with serotype 4 antiserum at $6.5 \mathrm{kDa}$ and exhibited serotype 3 reactivity at 7.8 or $7.5 \mathrm{kDa}$. However, LPS from the commercial vaccine preparations did not react with serotype 3 antiserum.

The sizes of the LPS bands from the vaccine preparations were appropriate for serotype 3 LPS; however, these bands did not react with the serotype 3 antisera. To elucidate the identity of the terminal carbohydrate, SBA lectin would reveal if the LPS molecules contained a terminal $\alpha$ or $\beta$ - $N$-acetyl-galactosamine as previously described for serotype $3(32,35)$. These results are shown in Table 3. Positive control P1059 demonstrated positive SBA reactivity in 7.8$6.5 \mathrm{kDa}$ molecular weight range. The vaccine strains had faint bands at 7.8 and $7.5 \mathrm{kDa}$. But SBA did not react with LPS from the 
Table 3. Serotype reactivity of (lipopolysaccharides) LPS isolated from Pasteurella multocida vaccine strains and commercial vaccine preparation.

\begin{tabular}{lcccc}
\hline & $\begin{array}{c}\text { LPS MW } \\
(\mathrm{kDa})\end{array}$ & $\begin{array}{c}\text { Serotype } \\
\text { 3 antiserum }\end{array}$ & $\begin{array}{c}\text { Serotype } \\
\text { 4 antiserum }\end{array}$ & SBA \\
\hline P1059 (Serotype 3) & 7.8 & + & - & + \\
P1662 (Serotype 4) & 7.5 & + & - & + \\
& 7.5 & - & + & - \\
CU & 6.3 & - & + & - \\
& 7.8 & + & + & + \\
& 7.5 & + & + & + \\
PM-1 & 6.3 & - & + & - \\
& 7.8 & + & + & + \\
M-9 & 7.5 & + & + & + \\
Commercial vaccine lot & 7.8 & + & + & + \\
(M-9-63B) & 7.8 & - & - & - \\
& 7.5 & - & - & - \\
Commercial vaccine lot & 6.3 & - & + & - \\
(M-9-60A) & 7.8 & - & - & - \\
& 7.5 & - & - & - \\
& 6.3 & - & + & - \\
\hline
\end{tabular}

commercial preparations, indicating that these bacterial cells were not producing the predicted serotype 3 LPS structure (Fig. 4).

In order to elucidate the composition of the variant LPS, glycosyl composition analysis was performed (Table 4); however, phosphoethanolamine, a component of core LPS in serotypes 3 and 4, would not have been detected with this method. Nearly all samples contained keto-deoxyoctulosonate residues confirming presence of a small percentage of core LPS. Additional components or breakdown products of core LPS such as $\mathrm{N}$-acetyl glucosamine, heptose, fatty acids (C14:0), and $\beta$-hydroxy fatty acids $(\mathrm{C} 12: \mathrm{OH}, \mathrm{C} 14: \mathrm{OH})$ were also observed in many of the samples. Consistent with previous reports $(14,35)$ of galactose and glucose in serotype 3 and 4 LPS, residues were also found in all samples. Sialic acid residues were detected in several $P$. multocida serotype 4 outbreak isolates and one of the vaccine preps. However, while heptose should represent at least $25 \%$ of the LPS outer core carbohydrate chain of serotype 4 , it was less than $15 \%$ of the vaccine lots and two of the outbreak isolates. In fact, the vaccine lots and $P$. multocida outbreak isolates 35 and 45 contained $36-72 \%$ rhamnose, suggesting that it may have

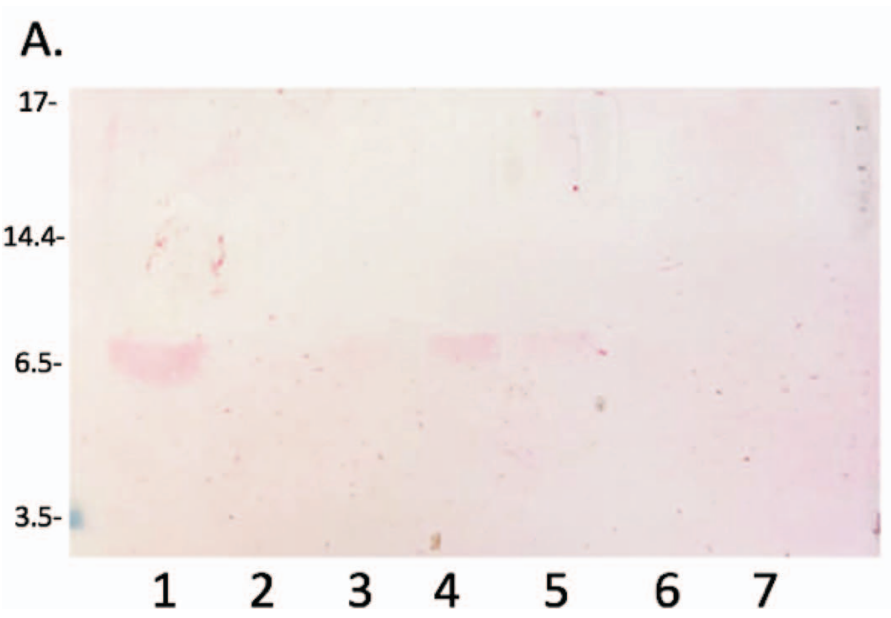

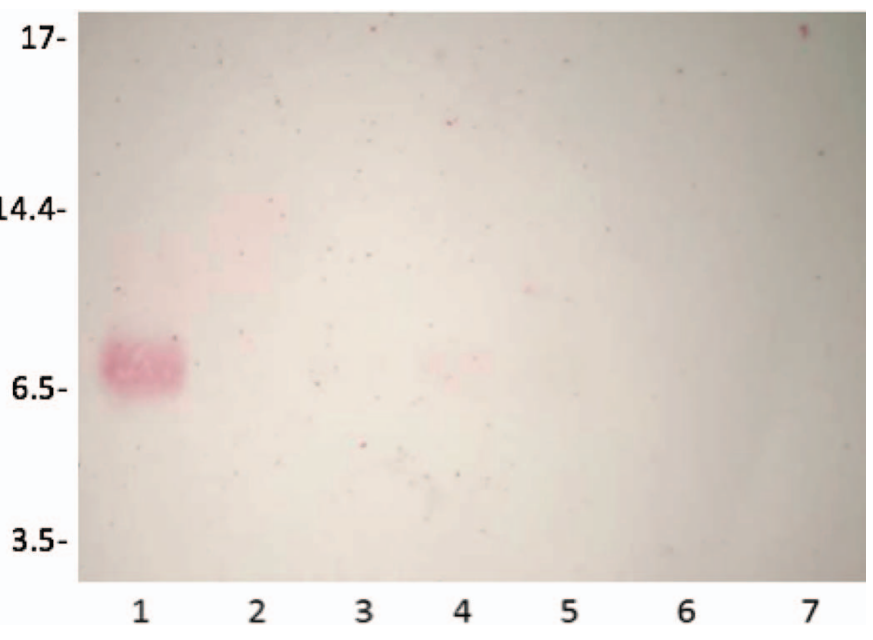

Fig. 4. SBA lectin probing of LPS isolated from vaccine strains and commercial vaccine preparations to detect terminal $\mathrm{N}$-acetyl-galactosamine. Lane 1: P1059 (serotype 3). Lane 2: P1662 (serotype 4). Lane 3: $\mathrm{CU}$ vaccine strain. Lane 4: PM-1 vaccine strain. Lane 5: M-9 vaccine strain. Lane 6: commercial vaccine lot M-9-63B. Lane 7: commercial vaccine lot M-9-60A.

replaced hexose in the LPS outer core. While it is known that serotype 4 LPS may exhibit multiple isoforms containing phosphoethanolamine (35), these results indicate that the LPS of the cells in the vaccine may be further modified, which not only would affect their serotype reactivity but may also affect immunogenicity of the vaccine and virulence of the strains.

\section{DISCUSSION}

Previous studies indicated that live $P$. multocida vaccines may have caused disease because the symptoms of disease occur soon after administration of a live vaccine $(37,38)$. Serotyping has not been very useful in detecting environmental outbreak isolates because the vaccine serotype 3,4 is one of the most common outbreak serotypes. Vaccine and environmental outbreak strains have been genetically differentiated by strain typing, but methods are time consuming and not easy to implement in a diagnostic lab (39). The goal of this

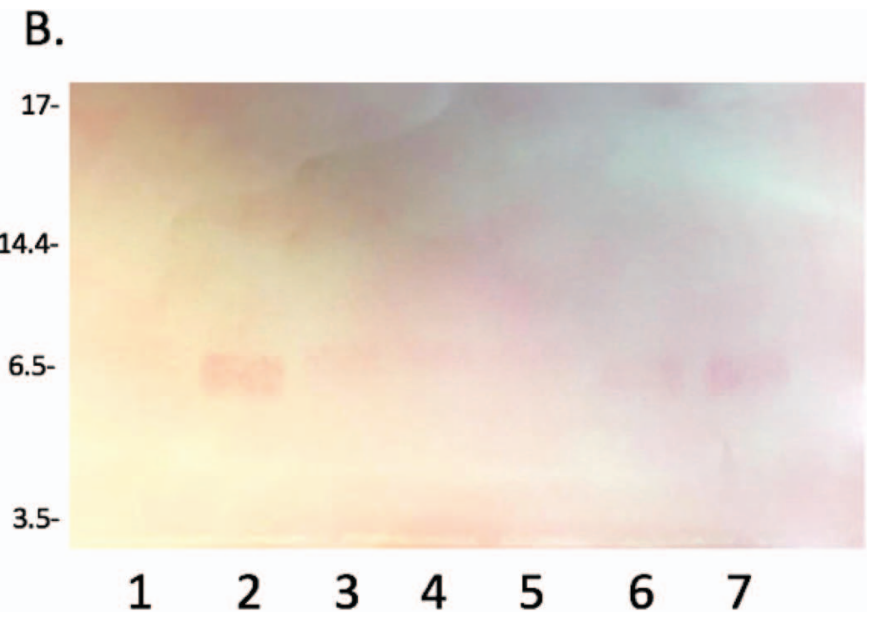

Fig. 3. Immunoblots of LPS isolated from vaccine strains and commercial vaccine preparations. Panel A: Immunoblot with serotype 3 antiserum. Panel B: Immunoblot with serotype 4 antiserum. Lane 1: P1059 (serotype 3). Lane 2: P1662 (serotype 4). Lane 3: CU vaccine strain. Lane 4: PM-1 vaccine strain. Lane 5: M-9 vaccine strain. Lane 6: commercial vaccine lot M-9-63B. Lane 7: commercial vaccine lot M-9-60A. 
Table 4. LPS glycosyl composition analysis of Pasteurella multocida serotype 4 outbreak isolates, commercial vaccines, and vaccine strains.

\begin{tabular}{|c|c|c|c|c|c|c|c|c|c|}
\hline \multirow[b]{2}{*}{ Glycosyl residue } & \multicolumn{9}{|c|}{ Mole $\%$ of total carbohydrates } \\
\hline & $35(\operatorname{ser} 4)$ & 37 (ser4) & Vaccine lot M-9-63B & $42(\operatorname{ser} 4)$ & $40^{\mathrm{A}}(\operatorname{ser} 4)$ & $46^{\mathrm{A}}(\operatorname{ser} 4)$ & $\mathrm{CU}(\operatorname{ser} 3,4)$ & $45^{\mathrm{A}}(\operatorname{ser} 4)$ & Vaccine lot M-9-60A ${ }^{\mathrm{A}}$ \\
\hline Rhamnose & 65.3 & - & 68.2 & 0.5 & - & 2.5 & - & 0.4 & 36.1 \\
\hline Mannose & - & 4.1 & - & 1.9 & 7.3 & 5.8 & 13.2 & 8.8 & 0.6 \\
\hline Galactose & 0.4 & 12.9 & 0.3 & 16.3 & 31.7 & 17.4 & 13.0 & 18.8 & 7.3 \\
\hline Glucose & 0.6 & 17.7 & 0.5 & 18.2 & 25.3 & 14.8 & 17.9 & 13.4 & 4.9 \\
\hline$N$-acetyl glucosamine & 20.4 & - & 18.8 & 4.0 & 5.8 & 6.0 & 13.1 & 8.8 & 18.0 \\
\hline Heptose & 1.9 & 65.3 & 1.8 & 52.8 & 27.6 & 49.1 & 42.8 & 43.9 & 14.9 \\
\hline Keto-deoxyoctulosonate & 2.2 & - & 1.4 & 6.3 & 2.1 & 4.5 & - & 5.6 & 4.0 \\
\hline $\mathrm{N}$-acetyl muramic Acid & - & - & - & - & 0.3 & - & - & - & - \\
\hline
\end{tabular}

${ }^{A}$ Sialic acid also detected at $<1 \%$.

research was to produce a vaccine-specific test to detect vaccinerelated disease. It was a surprising finding that vaccine-related fowl cholera occurred from serotype 4 isolates that were the same as the vaccine strain.

In this study, we documented that vaccine-related fowl cholera outbreaks were caused by both serotype 3,4 and 4 isolates and that outbreaks were common in vaccinated broiler breeders. Although all commercial live vaccine strains derived from a single $P$. multocida 3,4 serotype isolate, the commercial live vaccine preps that caused vaccine-related fowl cholera may react poorly with serotype 3 antiserum and strongly with serotype 4 antiserum. The purified LPS isolated from vaccine lots and outbreak strains reacted only with serotype 4 antiserum. SBA lectin confirmed that serotype 3 LPS was absent in commercial vaccine preparations. Chemical analysis of the LPS from serotype 4 outbreak strains and the commercial vaccine preparations indicated that they expressed variant LPS structures. Variant LPS was described in highly virulent serotype 3,4 isolate 861913, where lectins identified serotype 4 specific terminal $\beta$-gal (RCA) and serotype 3 specific $N$-acetyl-galactosamine (SBA) LPS structures whose expression correlated with virulence [31]. Pasteurella multocida 86-1913 colonies that expressed terminal galactose were highly virulent, but those that expressed $N$-acyl-galactosamine but not $\beta$-gal were avirulent. This suggested that virulence was enhanced by serotype 4 LPS.

In this study, Heddleston serotyping revealed that the two commercial $P$. multocida vaccine preparations that were associated with clinical disease contained primarily serotype 4 cells. In addition, the serotype 4 vaccine-related outbreak strains expressed variant LPS, indicating that the cross-protective ability of these vaccine preparations was likely compromised. While serotyping will not detect vaccine-related serotype 4 outbreak isolates, the vaccinespecific PCR can efficiently detect outbreak related vaccine strains and can be implemented easily for diagnostic use. Additionally, all lots of live fowl cholera vaccine should be titered serotyped prior to use in order to reduce the incidence of vaccine-related disease in broiler breeders.

\section{REFERENCES}

1. Olsen I, Dewhirst FE, Paster BJ, Busse HJ. Family Pasteurellaceae. In: Brenner DJ, Krieg N, Staley JT, Garrity GM, editors. Bergey's manual of systematic bacteriology. New York: Springer. p. 851-856; 2005.

2. Calnek BW. Diseases of poultry. Ames (IA): Iowa State University Press; 1997.
3. Christensen JP, Bojesen AM, Bisgaard M. Fowl cholera. In: Pattison M, McMullin P, Bradbury JM, Alexander DJ, editors. Poultry Diseases. 6th ed. London: Saunders Elsevier. p. 149-154; 2008.

4. Carpenter TE, Snipes KP, Wallis D, McCapes R. Epidemiology and financial impact of fowl cholera in turkeys: a retrospective analysis. Avian Dis.16-23; 1988.

5. Dorsey T, Harshfield G. Studies on control of fowl cholera. Technical Bulletin 53. Brookings (SD): SDSU; 1959.

6. Heddleston K, Gallagher J, Rebers P. Fowl cholera: gel diffusion precipitin test for serotyping Pasteurella multocida from avian species. Avian Dis. 16:925-936; 1972.

7. Blackburn BO, Heddleston KL, Pfow CJ. Pasteurella multocida serotyping results (1971-1973). Avian Dis. 19:353-356; 1975.

8. Carter GR. Pasteurellosis: Pasteurella multocida and Pasteurella hemolytica. Adv Vet Sci. 11:321-79; eng. 1967.

9. Rimler R, Rhoades K. Serogroup F, a new capsule serogroup of Pasteurella multocida. J Clin Microbiol. 25:615-618; 1987.

10. Rhoades KR, Rimler R. Pasteurellosis. In: Calnek BW, Barnes H, Beard CW, Reid WM, Yoder HW Jr, editors. Diseases of poultry. 9th ed. Ames (IA): Iowa State University Press. p. 145-162; 1991.

11. Glisson JR, Hofacre CL. Pasteurella multocida vaccine. [07/ 190,533]: USPTO; 4,999,191; 1991.

12. Marshall MS. Development of an attenuated fowl cholera vaccine. Provo (UT): Brigham Young University; 1981.

13. Bierer B. Comparison of a live drinking water vaccine for fowl cholera in turkeys to a killed drinking water vaccine and to five injected commercial bacterins. Poult Sci. 48:633-636; 1969.

14. Harper M, John M, Turni C, Edmunds M, St Michael F, Adler B, Blackall PJ, Cox AD, Boyce JD. Development of a rapid multiplex PCR assay to genotype Pasteurella multocida strains by use of the lipopolysaccharide outer core biosynthesis locus. J Clin Microbiol. 53:477-85; 2015.

15. Lee MD, Burch FT, Maurer JJ, Henk A, Thayer S. DNA fingerprinting of plasmid-containing serotype A: 3, 4 Pasteurella multocida isolated from cases of fowl cholera in chickens and turkeys. Avian Dis. 44:201-204; 2000.

16. Snipes KP, Hirsh DC, Kasten RW, Carpenter TE, Hird DW, McCapes RH. Differentiation of field isolates of Pasteurella multocida serotype 3, 4 from live vaccine strain by genotypic characterization. Avian Dis. 34:419-424; 1990.

17. Bierer B, Derieux W. Immunologic response of turkey poults of various ages to an avirulent Pasteurella multocida vaccine in the drinking water. Poult Sci. 54:784-787; 1975.

18. Maheswaran SK, Thies ES. Influence of encapsulation on phagocytosis of Pasteurella multocida by bovine neutrophils. Infect Immun. 26:76-81; 1979.

19. Patel RK, Jain M. NGS QC Toolkit: a toolkit for quality control of next generation sequencing data. PLoS One. 7(2):1-7; 2012.

20. Afgan E, Baker D, Batut B, van den Beek M, Bouvier D, Cech M, Chilton J, Clements D, Coraor N, Gruning BA, et al. The Galaxy platform for accessible, reproducible and collaborative biomedical analyses: 2018 update. Nucleic Acids Res. 46(W1):W537-W544; 2018. 
21. Zerbino D, Birney E. Velvet: algorithms for de novo short read assembly using de Bruijn graphs. Genome Res. gr. 074492.107; 2008.

22. Overbeek R, Olson R, Pusch GD, Olsen GJ, Davis JJ, Disz T, Edwards RA, Gerdes S, Parrello B, Shukla M, et al. The SEED and the Rapid Annotation of microbial genomes using Subsystems Technology (RAST). Nucleic Acids Res. 42:D206-D214; 2014.

23. Sievers F, Wilm A, Dineen D, Gibson TJ, Karplus K, Li W, Lopez R, McWilliam H, Remmert M, Söding J, et al. Fast, scalable generation of high-quality protein multiple sequence alignments using Clustal Omega. Mol Syst Biol. 7:539; 2011.

24. Kumar S, Stecher G, Li M, Knyaz C, and Tamura K. MEGA X: Molecular Evolutionary Genetics Analysis across computing platforms. Mol Biol Evol. 35:1547-1549; 2018.

25. Altschul SF, Gish W, Miller W, Myers EW, Lipman DJ. Basic local alignment search tool. J Mol Biol. 215:403-410; 1990.

26. Untergasser A, Nijveen H, Rao X, Bisseling T, Geurts R, Leunissen JAM. Primer3Plus, an enhanced web interface to Primer3. Nucleic Acids Res. 35: W71-W74; 2007. doi: 10.1093/nar/gkm306.

27. Gunawardana GA, Townsend KM, Frost AJ. Molecular characterisation of avian Pasteurella multocida isolates from Australia and Vietnam by REP-PCR and PFGE. Vet Microbiol. 72:97-109; 2000.

28. Koort JMK, Lukinmaa S, Rantala M, Unkila E, Siitonen A. Technical improvement to prevent DNA degradation of enteric pathogens in pulsed-field gel electrophoresis. Journal of Clinical Microbiology, 40:3497-3498; 2002.

29. Hitchcock PJ, Brown TM. Morphological heterogeneity among Salmonella lipopolysaccharide chemotypes in silver-stained polyacrylamide gels. J Bacteriol. 154:269-277; 1983.

30. Towbin H, Staehelin T, Gordon J. Electrophoretic transfer of proteins from polyacrylamide gels to nitrocellulose sheets: procedure and some applications. Proc Natl Acad Sci USA. 76:4350-4354; 1979.

31. Coy SL, Lee MD, Sander J. Intrastrain variation of lipopolysaccharide of Pasteurella multocida in turkeys. Athens (GA): University of Georgia; 1996.

32. Ravidà A, Musante L, Kreivi M, Miinalainen I, Byrne B, Saraswat M, Henry M, Meleady P, Clynes M, Holthofer H. Glycosylation patterns of kidney proteins differ in rat diabetic nephropathy. Kidney Intl. 87:963-974; 2015.

33. Santander J, Martin T, Loh A, Pohlenz C, Gatlin III DM, Curtiss III R. Mechanisms of intrinsic resistance to antimicrobial peptides of
Edwardsiella ictaluri and its influence on fish gut inflammation and virulence. Microbiol. 159:1471; 2013.

34. Horvath P, Barrangou R. CRISPR/Cas, the immune system of bacteria and archaea. Science 327:167-170; 2010.

35. Harper M, St Michael F, John M, Vinogradov E, Steen JA, van Dorsten L, Steen JA, Turni C, Blackall PJ, Adler B, et al. Pasteurella multocida Heddleston serovar 3 and 4 strains share a common lipopolysaccharide biosynthesis locus but display both inter- and intrastrain lipopolysaccharide heterogeneity. J Bacteriol. 195:4854-64; 2013.

36. Harper M, Wright A, St Michael F, Li J, Deveson Lucas D, Ford M, Adler B, Cox AD, Boyce JD. Characterization of two novel lipopolysaccharide phosphoethanolamine transferases in Pasteurella multoci$d a$ and their role in resistance to cathelicidin-2. Infect Immun, 85:e0055717; 2017. doi: 10.1128/IAI.00557-17.

37. Hofacre CL, Glisson JR, Kleven SH, Brown J, Rowland JN. Evaluation of Pasteurella multocida mutants of low virulence. I. Development and pathogenicity. Avian Dis. 33:270-274; 1989.

38. Hofacre CL, Glisson JR, Kleven SH. Evaluation of Pasteurella multocida mutants of low virulence. II. Immunologic response of turkeys. Avian Dis. 33:275-278; 1989.

39. Schlink GT, Olson LD. Vaccination of turkey breeder hens and toms for fowl cholera with CU strain. Avian Dis. 31: 29-38; 1987.

\section{ACKNOWLEDGMENTS}

AH performed most of the experiments with the outbreak isolates and vaccine preps; CL and HS performed the initial isolation, identification, and serotyping of the outbreak isolates; SR and KG provided clinical assessment of suspect flocks; NF provided guidance on PCR development; KT supervised laboratory experiments; ML and JM supervised the research project. In addition to the funding from the Poultry Diagnostic and Research Center for characterizing the outbreak strains and developing the PCR, the carbohydrate analysis was supported by the Chemical Sciences, Geosciences and Biosciences Division, Office of Basic Energy Sciences, U.S. Department of Energy grant (DE-SC0015662) to Parastoo Azadi at the Complex Carbohydrate Research Center. 